\title{
Electrochemical discharge machining: A review
}

\author{
Uğur ÖZMEN \\ Selçuk University, \\ Faculty of Technology, \\ Mechanical Engineering \\ Konya, Turkey
}

\author{
İlhan ASILLTÜRK \\ Selçuk University, \\ Faculty of Technology, \\ Mechanical Engineering \\ Konya, Turkey
}

\begin{abstract}
In this study, progress and sort of electrochemical discharge machining (ECDM) that was developed to manufacture the micro features like micro grooves, micro pillar, micro holes and micro channels etc. were investigated. Many materials can be machined regardless of material conductivity, hardness and strength by ECDM using electro chemical machining (ECM) and electric discharge machining (EDM) combination. Researchers developed electrochemical discharge drilling (ECDD), turning (ECDT), grinding (ECDG), milling, dressing, trepanning, wire ECDM, die-sinking ECDM, rotary ECDM, powder mixed ECDM, magnetic field assisted ECDM, vibration assisted ECDM methods. Pyrex, glass, stainless steel, cermet, soda lime glass, quartz, silicon nitride, zirconium oxide, borosilicate glass, diamond crystals, e-glass/epoxy composite, kevlar/epoxy composite and silicon wafer were used as a work piece. Effects of machining voltage and drilling depth on mean diameter, influence of tool travel rate on groove width and depth and effects of voltage types on micro holes accuracy and machining type etc were investigated. This review is to discuss the results of studies and applicability of this methods. It sums up also with a vision for future research in electrochemical micromachining.
\end{abstract}

Keywords: Electro chemical machining (ECM), electric discharge machining (EDM), electrochemical discharge machining (ECDM), micro machining

\section{INTRODUCTION}

Increase of utilization of micro scale products in wide range of science and technology fields leads researchers to investigate more about these fields. Electrochemical machining (ECM) only for electrically conductive materials, electric discharge machining (EDM) for electrically conductive materials and non-conductive materials only with specific set-up remain incapable of manufacturing of micro scale products. Thus, researchers have been tried to find new hybrid methods to manufacture micro scale products irrespective of material conductivity and strength. Electrochemical discharge machining (ECDM) that is a combination of ECM and EDM was developed by Kurafuji and Suda in 1968[1] but it was first described by physicists Hippolyte Fizeau (1819-1896) and Leon Foucault (18191868) [2]. The basic configuration of ECDM was shown in Fig 1[3]. Researchers developed new processes, the same with ECDM essentially, in times. In this study, these new kinds of ECDM processes and investigations to enhance material removal rate (MRR) of ECDM were analysed.

\section{ECDM IN LITERATURE}

Before to develop the ECDM, researchers tried to understand the electrochemical discharge phenomenon. One of the first investigations on this is the effect of different power supply configurations and electrolytes in 1993 by Raghuram et al. [4]

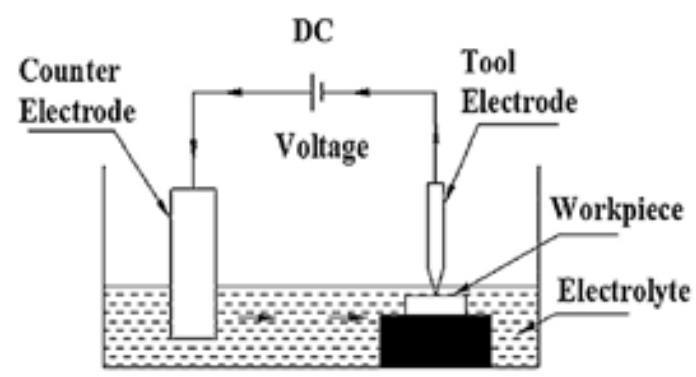

Figure. 1 Basic cell configuration in electro-chemical discharge machining [3]

\subsection{ECDM}

Because, the critical voltage was important to determine the material removal rate and enhance MRR. Basak and Ghosh [5] developed a model and compare numerical results with experimental ones to predict the MRR. Besides, Ghosh [6] presented the principle and possibilities of ECDM. Among early works in literature, Bhattacharyya et al. [7] analyzed different process parameters on MRR and they attempted to specify the proper tool shape. Kulkarni et al. [8] were the other researchers to investigate the mechanism of the ECDM process. They paid attention to relation among the timevarying current, temperature rise and MRR. A mathematical model was developed to relate among machining parameters with process criteria by Sarkar et al. [9]. Conclusions showed that applied voltage had more effects on material removal rate, radial overcut and heat affected zone. Chavoshi and Behagh [10] investigated and discussed the hole length and axial wear parameters and relation between them. That results were cited from the paper by Coteate[11]. The influences of process parameters of ECDM on MRR were researched for borosilicate glass and process parameters were optimized using Taguchi's method by Paul and Hiremath [12]. Adding surfactant to electrolyte increased the current density and stabilized the current, hence provide better quality [13]. Hajian et al. [14] investigated effects of magnetic field orientation on ECDM performance and concluded that magnetic field orientation increased channel depth and surface quality. Behroozfar and Razfar studied characteristics on the plasma channel and material removal [15] and tool wear [16] during ECDM. Dhanvijay and Ahuja [17] studied machining parameters of stagnant and electrolyte flow method on ECDM and obtained the results that electrolyte flow method had a high MRR but a high diametric overcut that had been minimized. A mathematical model was developed by Kamaraj at el. [18] to predict the overcut of the surface that was important to protect the product dimensions. They also produced micro tools in-house and used them to drill glass. 
Gupta et al. [19] investigated the effect of duty ratio on MRR, depth of penetration, surface damage and heat effected zone. Ladeesh and Manu [20] focused on the effects of voltage, duty cycle, cycle time and electrolyte concentration on material remove with response surface methodology. Aspect ratio is also one of the conspicuous subjects on ECDM like Gupta et al. [21] studied the effect of pulse duration on aspect ratio of glass material. Although quartz is a kind of glass, it has different characteristics. The effects of electrolyte and pulse properties on ECDM characteristics of quartz were investigated by Nguyen et al [22].

\subsection{ECDM Hybrids}

Chak et al. [23] developed new tools for electrochemical discharge drilling to prevent the decrease on MRR with increasing machining depth. Spring-fed cylindrical hollow brass tool and spring-fed cylindrical abrasive tool were used to drill aluminium oxide (A12O3). Coteate et al. emphasized the effects of some parameters (the voltage, the electrode tool diameter and the work liquid density) on the electrode tool wear [24], the effects of the input parameters on the tool wear and on the drilling speed [25], the effects of the voltage, the capacity of electric circuit on tool wear [11]. They also designed, built and tested an in-house equipment on ECDD process with passivating electrolyte [26].

Nguyen et al. used the simultaneous micro ED/EC milling method which enhanced surface integrity and dimensional accuracy to the situation that these methods used alone [27], and they studied analytical model to describe critical conditions for MR mechanisms for these methods [28].

Zeng et al. [29] combined the methods, EDM for shaping and ECM for finishing, and had results that the size and shape of workpiece was much better than which were milled by only ECM.

Liu et al. [30] developed new wire ECDM process to machine particle-reinforced aluminium alloy 6061 and researched the influences of current, pulse duration and electrolyte concentration on MRR. Results indicated that most effective factor for the highest MRR is the applied current. Again, they [31] developed a grinding-aided model to machine particulate reinforced metal matrix composites (MMCs). This new method enhanced efficiency of machining and surface quality on MMCs. Also to predict of critical breakdown voltage they developed a model [32] corresponding with experimental results. Cao et al. [33] machined 3D micro-structures less than $100 \mu \mathrm{m}$ in size and achieved good surface in spite of minimized structures (Fig 2). It was revealed that high voltage reduced machining resolution. Thus, they reduced required voltage by means of a load cell and the tool electrode with small layer depth. Cao et al [34] also used ECDM and micro grinding process for machining of glass type material that had an important disadvantage, rough surface, using polycrystalline diamond (PCD) tool.

Cheng et al. [35] investigated the influences of the machining parameters on gas film quality which is very important factor on machining quality. Again, they [36] used new process wire ECDM with electrolyte supplied in titrated flow to fabricate the micro-scale features. The results remarked that this new cost effective and environmental friendly process enable better machining outcomes with less width. They revealed [37] that adding $\mathrm{SiC}$ powder improved surface quality up to $80 \%$. Finite element based model for ECDM drilling was developed to predict discharge regime by Wei et al [38].
Jiang et al. [39] determined spark energy to model spark generation and this finite element model were validated with experiments. They [40] also modelled gas film evolution and
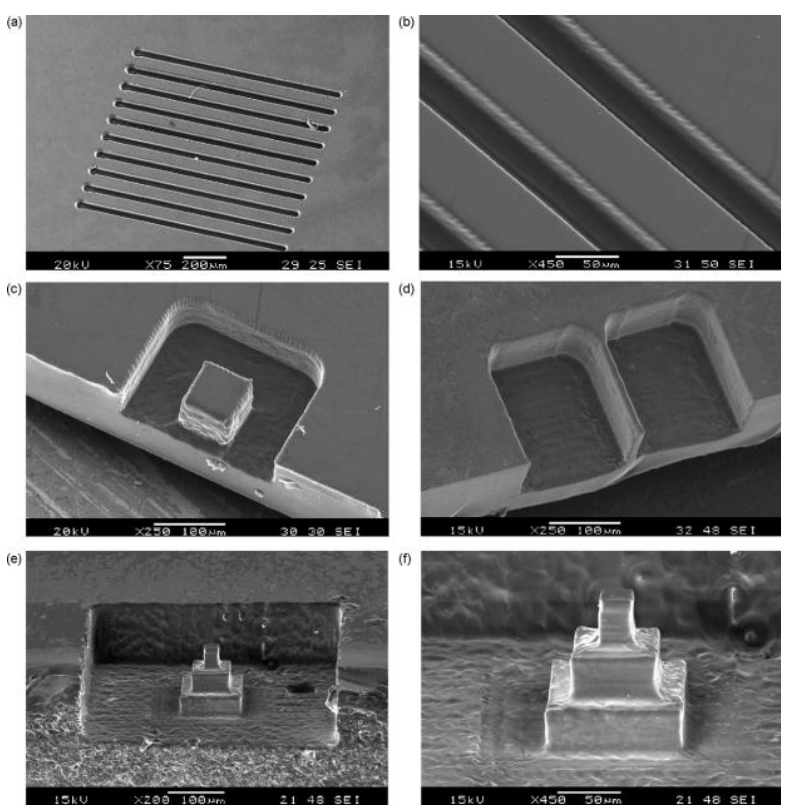

Figure. 2 (a) Micro grooves, (b) enlarged figure of micro-grooves, (c) micro-pillar, (d) micro-wall, (e and f) micro-pyramid machined on glass by ECDM (KOH $30 \mathrm{wt} \%, 23 \mathrm{~V}$ pulse voltage, $1 \mathrm{~ms} / 1 \mathrm{~ms}$ pulse on/off-time ratio, $\varnothing 30-33 \mu \mathrm{m}$ tool, $3 \mu \mathrm{m} / \mathrm{s}$ federate and $300 \mathrm{rpm}$ rotational speed) [33]

validated with experiments to enhance the machining efficiency and quality. The properties of electrochemical discharge effect were investigated by them [41]. Razfar et al. [42] studied effects of different types of longitudinal oscillation on machining speed and hole depth. Results revealed that although vibration did not effect on the process with micro drill, it was quite effective such as MRR up to $40 \%$ with cylindrical rod. Advantages of electrochemical discharge drilling were revealed by Skrabalak and Stwora [43] on the comparison study drilling hole with electrochemical, electro discharge and electrochemical discharge drilling.

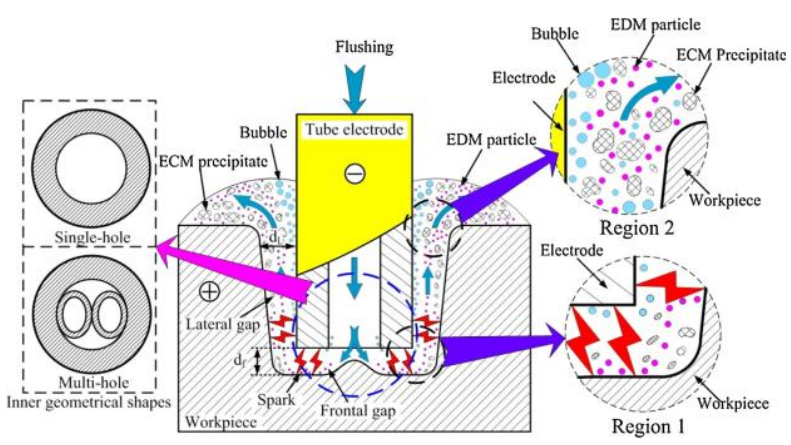

Figure..3 Mechanism of TEHECDD for different inner geometrical shapes [45]

Zhang et al. [44, 45, 46, 47, 48, 49] developed new process, tube electrode high-speed electrochemical discharge drilling (TSECDD), shown in Fig 3, to machine cooling holes. Lowconductivity salt solution [44] enhanced machining surface and efficiency, increasing tube-electrode inner diameter increased MRR [45] on TSECDD. The performance of ECDD 
with super-high-pressure interior flushing [47] and internal and side flushing [48] were investigated with machining parameters effects. Effect of tube electrode inner diameter on ECDM of nickel-based superalloy which are widely used in aircraft engines were studied [49].

304 stainless steel was drilled with ECDM process by Huang et al. [50] who established a new process using high-speed micro-electrode. Liu et al. [51] analysed the inter-polar voltage and characteristics of current of a process using slotted metal wheel and mist-jetting electrolyte in ECDM to stabilize. Krötz and Wegener [52] developed a new process that was spark assisted electrochemical machining (SAEM). The process is shown in Fig. 4. This process was stimulating more contact arcs in a period on the contrary of ECDM. This method presented that the finishing could be done with the same equipment. They also revealed [53] that comprehending the heat distribution would enabled further improvement of this method. Electrochemical spark machining method was interested by some researchers $[54,55,56]$. Ziki and Wüthrich [56] used spark assisted method for gravity-feed micro hole machining. They investigated tool wear and expansion for tungsten, steel and stainless electrodes.

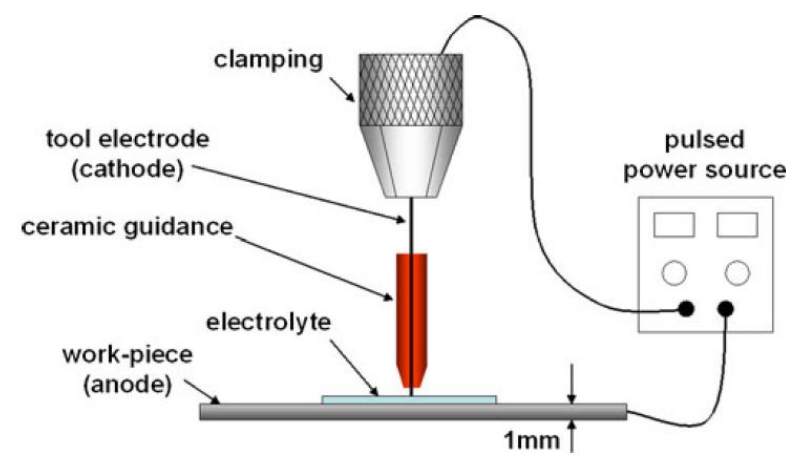

Figure 2. Example of a One-Column figure caption.

\section{CONCLUDING REMARKS}

The aim of this study was analysing the ECDM investigations and new processes of ECDM. Researchers, especially investigated and emphasized the material removal rate that was very crucial to improve the ECDM process. It was seen obviously that applied current [30] is the most effective parameter on MRR. New tools [23], tool shapes [7] or new processes $[42,17]$ were developed to enhance MRR. Besides, applied voltage is very effective on MRR [9]. Yet, Cao et al. [33] emphasized that high voltage reduced the machining resolution. Future works will be carried out in ECDM in the light of the results.

\section{REFERENCES}

[1] H. Karafuji and K. Suda, "Electrical discharge drilling of glass," Ann CIRP, vol. 16, 415-419, 1968.

[2] H. Fizeau, L. Foucault, "Annales de Chimie et de Physique XI(3éme série),” 370, 1844.

[3] M. Goud, A.K. Sharma and C. Jawalkar, "A review on material removal mechanism in electrochemical discharge machining (ECDM) and possibilities to enhance the material removal rate," Precision Engineering, vol. 45, 1-17, 2016.
[4] V. Raghuram, T. Pramila, Y.G. Srinivasa and K. Narayanasamy, "Effect of the circuit parameters on the electrolytes in the electrochemical discharge phenomenon," Journal on Materials Processing Technology, vol. 52, 301318, 1995.

[5] I. Basak and A. Ghosh, "Mechanism of material removal in electrochemical discharge machining: a theoretical model and experimental verification, Journal Processing Technology, vol. 71, 350-359, 1997.

[6] A. Ghosh, "Electrochemical discharge machining: Principle and possibilities," Sadhana, vol. 22, part 3, 435-447, Jun. 1997.

[7] B. Bhattacharyya, B.N. Doloi and S.K. Sorkhel, "Experimental investigations into electrochemical discharge machining (ECDM) of non-conductive ceramic materials," Journal of Materials Processing Technology, vol. 95, 145154, 1999.

[8] A. Kulkarni, R. Sharan and G.K. Lal, "An experimental study of discharge mechanism in electrochemical discharge machining," International Journal of Machine Tools \& Manufacture, vol. 42, 1121-1127, 2002.

[9] B.R. Sarkar, B. Doloi and B. Bhattacharyya, "Parametric analysis on electrochemical discharge machining of silicon nitride ceramics, Int J Adv Manuf Technol, vol. 28, 873-881, 2006.

[10] S. Z. Chavoshi and A.M. Behagh, "A note on influential control parameters for drilling of hard-to-machine steel by electrochemical discharge machining," Int J Adv Manuf Technol, vol. 71, 1883-1887, 2014.

[11] M. Coteata, H.P. Schulze and L. Slatineanu, "Drilling of Difficult-to-Cut Steel by Electrochemical Discharge Machining," Materials and Manufacturing Processes, vol. 26, 1466-1472, 2011.

[12] L. Paul and S.S. Hiremath, "Response Surface Modelling of Micro Holes in Electrochemical Discharge Machining Process," Procedia Engineering, vol. 64, International Conference On DESIGN AND MANUFACTURING, IconDM 2013, 1395-1404.

[13] Y.S. Laio, L.C. Wu and W.Y. Peng, "A study to improve drilling quality of electrochemical discharge machining (ECDM) process," Procedia CIRP, vol. 6, The Seventeenth CIRP Conference on Electro Physical and Chemical Machining (ISEM) 2013, 609-614.

[14] M. Haijan, M.R. Razfar and Saeid Movahed, "An experimental study on the effect of magnetic field orientations and electrolyte concentrations on ECDM milling performance of glass," Precision Engineering, vol. 45, 323-331, 2016.

[15] A. Behroozfar and M.R. Razfar, "Experimental and Numerical Study of Material Removal in Electrochemical Discharge Machining (ECDM)," Materials and Manufacturing Processes, vol. 31, 495-503, 2016.

[16] A. Behroozfar and M.R. Razfar, "Experimental Study of the Tool Wear During the Electrochemical Discharge Machining," Materials and Manufacturing Processes, vol. 31, 574-580, 2016 
[17] M.R. Dhanvijay and B.B. Ahuja, "Micromachining of ceramics by Electrochemical Discharge process considering stagnant and electrolyte flow method," Procedia Technology, vol. 14, $2^{\text {nd }}$ International Conference on Innovations in Automation and Mechatronics Engineering, ICIAME 2014 165-172.

[18] A.B. Kamaraj, S.K. Jui, Z. Cai and M.M. Sundaram, “A mathematical model to predict overcut during electrochemical discharge machining," Int J Adv Manuf Technol, vol. 81, 685$691,2015$.

[19] P.K. Gupta, J.P. Bhamu, C.S. Rajoria, N.K. Lautre and V. Agarwai, "Effect of Duty Ratio at Different Pulse Frequency during Hole Drilling in Ceramics Using Electrochemical Discharge Machining," MATEC Web of Conferences, 77, 10004, 2016.

[20] V.G. Ladeesh and R. Manu, "Experimental Investigation on the Performance of Grinding Assisted Electrochemical Discharge Drilling of Glass," MATEC Web of Conferences, 51, 03001, 2016.

[21] P.K. Gupta, A. Dvivedi and P. Kumar, "Effect of Pulse Duration on Quality Caharacteristics of Blind Hole Drilled in Glass by ECDM," Materials and Manufacturing Processes, vol. 31, 1740-1748, 2016

[22] K.H. Nguyen, P.A. Lee and B. H. Kim, "Experimental Investigation of ECDM for Fabricating Micro Structures of Quartz, International Journal of Precision Engineering and Manufacturing, vol. 16, no. 1, 5-12, 2015.

[23] K. Sanjay, P. Chak and R. Venkateswara, "The drilling of $\mathrm{Al}_{2} \mathrm{O}_{3}$ using a pulsed DC supply with a rotary abrasive electrode by the electrochemical discharge process," Int $J A d v$ Manuf Technol, vol. 39, 633-641, 2008.

[24] M. Coteata, L. Slatineanu, O. Dodun and C. Ciofu, "Electrochemical discharge machining of small diameter holes," Int J Mater Form, 1327-1330, 2008.

[25] M. Coteata, C. Ciofu, L. Slatineanu, A. Munteanu and O. Dodun, "ESTABLISHING THE ELECTRICAL DISCHARGES WEIGHT IN ELECTROCHEMICAL DISCHARGE DRILLING," Int J Mater Form, vol. 2, 673676, 2009.

[26] M. Coteate, N. Pop, H.P. Schulze, L. Slatineanu and O. Dodun, "Investigation on hybrid electrochemical discharge drilling process using passivating electrolyte," $18^{\text {th }}$ CIRP Conference on Electro Physical and Chemical Machining (ISEM XVIII), Procedia CIRP, 42, 778-782, 2016.

[27] M.D. Nguyen, M. Rahman and Y.S. Wong, "Enhanced surface integrity and dimensional accuracy by simultaneous micro-ED/EC milling," CIRP Annals-Manufacturing Technology, 61, 191-194, 2012.

[28] M.D. Nguyen, M. Rahman and Y.S. Wong, "Transitions of micro-EDM/SEDCM/micro-ECM milling in lowresistivity," International Journal of Machine Tools \& Manufacture, 69, 48-56, 2013.

[29] Z. Zeng, Y. Wang, Z. Wang, D. Shan and X. He, "A study of micro-EDM and micro-ECM combined milling for
3D metallic micro-structures," Precision Engineering, 36, 500-509, 2012.

[30] J.W. Liu, T.M. Yue and Z.N. Guo, "Wire Electrochemical Discharge Machining of $\mathrm{Al}_{2} \mathrm{O}_{3}$ Particle Reinforced Aluminum Alloy 6061," Materials and Manufacturing Processes, vol. 24, 446-453, 2009.

[31] J.W. Liu, T.M. Yue and Z.N. Guo, "Grinding-aided electrochemical discharge machining of particulate reinforced metal matrix composites," Int J Adv Technol, vol. 68, 23492357,2013

[32] J.W. Liu, T.M. Yue and Z.N. Guo, "An analysis of the discharge mechanism in electrochemical discharge machining of particulate reinforced metal matrix composites," International Journal of Machine Tools \& Manufacture, vol. 50, 86-96, 2010

[33] X.D. Cao, B.H. Kim and C.N. Chu, "Micro-structuring of glass with features less than $100 \mu \mathrm{m}$ by electrochemical discharge machining," Precision Engineering, vol. 33, 459$465,2009$.

[34] X.D. Cao, B.H. Kim and C.N. Chu, "Hybrid Micromachining of Glass Using ECDM and Micro Grinding," International Journal of Precision Engineering and Manufacturing, vol. 14, no.1, 5-10, 2013.

[35] C.P. Cheng, K.L. Wu, C.C. Mai, C.K. Yang, Y.S. Hsu and B.H. Yan, "Study of gas film quality in electrochemical discharge machining," International Journal of Machine Tools \& Manufacture, vol. 50, 689-697, 2010.

[36] K.Y. Kuo, K.L. Wu, C.K. Yang and B.H. Yan, "Wire electrochemical discharge machining (WECDM) of quartz glass with titrated electrolyte flow," International Journal of Machine Tools \& Manufacture, vol. 72, 50-57, 2013.

[37] K.Y. Kuo, K.L. Wu, C.K. Yang and B.H. Yan, "Effect of adding $\mathrm{SiC}$ powder on surface quality of quartz glass microslit machined by WECDM," Int J Adv Manuf Technol, vol. 78, $73-83,2015$.

[38] C. Wei, K. Xu, J. Ni, A.J. Brzezinski and D. Hu, "A finite element based model for electrochemical discharge machining in discharge regime," Int J Manuf Technol, vol. 54, 987-995, 2011

[39] B. Jiang, S. Lan, J. Ni and Z. Zhang, "Experimental investigation of spark generation in electrochemical discharge machining of non-conducting materials," Journal of Materials Processing Technology, vol. 214, 892-898, 2014.

[40] B. Jiang, S. Lan, K. Wilt and J. Ni, "Modeling and experimental investigation of gas film in microelectrochemical discharge machining process," International Journal of Machine Tools \& Manufacture, vol. 90, 8-15, 2015.

[41] Z. Zhang, L. Huang, Y. Jiang, G. Liu, X. Nie, H. Lu and H. Zhuang, "A study to explore the properties of electrochemical discharge effect based on pulse power supply,” Int J Adv Manuf Technol, vol. 85, 2107-2114, 2016.

[42] M.R. Razfar, A. Behroozfar and J. Ni, "Study of the effects of tool longitudinal oscillation on the machining speed 
of electrochemical discharge drilling of glass," Precision Engineering, vol. 38, 885-892, 2014.

[43] G. Skrabalak and A. Stwora," $18^{\text {th }}$ CIRP Conference on Electro Physical and Chemical Machining (ISEM XVIII), Procedia CIRP 42, 766-771, 2016.

[44] Y. Zhang, Z. Xu, D. Zhu and J.Xing, "Tube electrode high-speed electrochemical discharge drilling using lowconductivity salt solution," International Journal of Machine Tools \& Manufacture, vol. 92, 10-18, 2015.

[45] Y. Zhang, Z. Xu, Y. Zhu and D. Zhu, "Effect of tubeelectrode inner structure on machining performance in tubeelectrode high-speed electrochemical discharge drilling," Journal of Materials Processing Technology, vol. 231, 38-49, 2016.

[46] Y. Zhang, Z. Xu, Y. Zhu and D. Zhu, "Machining of a film-cooling hole in a single-crystal superalloy by high-speed electrochemical discharge drilling," Chinese Journal of Aeronautics, vol. 29/2, 560-570, 2016.

[47] Y. Zhang, Z. Xu, J. Xing and D. Zhu, "Enhanced Machining Performance of Micro Holes Using Electrochemical Discharge Machining with Super-HighPressure Interior Flushing," Int J Electrochem Sci, vol. 10, 8465-8483, 2015.

[48] Y. Zhang, Z. xu, D. Zhu, N. Qu and Y. Zhu, "Drilling of film cooling holes by a EDM/ECM in situ combined process using internal and side flushing of tubular electrode," Int $J$ Adv Manuf Technol, vol. 83, 506-517, 2016.

[49] Z. Yan, X. Zhengyang, X. Jun and Z. Di, "Effect of tubeelectrode inner diameter on electrochemical discharge machining of nickel-based superalloy," Chinese Journal of Aeronautics, vol. 29(4), 1103-1110, 2016.
[50] S.F. Huang, Y. Liu, J. Li, H.X. Hu and L.Y. Sun, "Electrochemical Discharge Machining Micro-Hole in Stainless Steel with Tool Electrode High-Speed Rotating," Materials and Manufacturing Processes, vol. 29, 634-637, 2014.

[51] Z. Liu, H. Chen, J. Yu and H. Pan, "Machining characteristics of hard and brittle insulating materials with mist-jetting electrochemical discharge," Int $J$ Adv Manuf Technol, vol. 79, 815-822, 2015.

[52] H. Krötz and K. Wegener, "Sparc assisted electrochemical machining: a novel possibility for microdrilling into electrical conductive materials using the electrochemical discharge phenomenon," Int J Adv Manuf Technol, vol. 79, 1633-1643, 2015.

[53] H. Krötz, R. Roth and K. Wegener, "Experimental investigation and simulation of heat flux into metallic surfaces due to single discharges in micro-electrochemical arc machining (micro-ECAM)," Int $J$ Adv Manuf Technol, vol. 68, 1267-1275, 2013.

[54] M.C. Panda and V. Yadava, "Intelligent Modeling and Multiobjective Optimization of Die Sinking Electrochemical Spark Machining Process," Materials and Manufacturing Processes, vol. 27, 10-25, 2012.

[55] N. Rattan and R.S. Mulik, "Improvement in material remocal rate(MRR) using magnetic field in TW-ECSM process," Materials and Manufacturing Processes, vol.32, no.1, 101-107, 2017.

[56] J.D.A. Ziki and R. Wüthrich, "Tool wear and tool thermal expansion during micro-machining by spark assisted chemical engraving," Int J Adv Manuf Technol, vol. 61, 481486, 2012. 